\title{
LAS IGLESIAS ORTODOXAS ENTRE LO GLOBAL, LO NACIONAL Y LO TRANSNACIONAL: APUNTES SOBRE EL CASO ESPAÑOL*
}

\author{
Orthodox churches between the global, the national and the transnational: \\ notes on the case of Spain
}

\author{
Francisco Díez de Velasco Abellán ** \\ Universidad de La Laguna \\ fradive@ull.edu.es
}

\author{
Óscar Salguero Montaño ${ }^{* * * *}$ \\ Universidad Complutense de Madrid \\ oscarsal@ucm.es
}

\begin{abstract}
Resumen
El caso de las iglesias ortodoxas y orientales en España resulta paradigmático para comprender la incidencia de los movimientos migratorios y las diásporas transnacionales sobre las particularidades nacionales de los distintos patriarcados presentes, que en la esfera pública se interrelacionan en mayor o menor grado en un contexto marcado por el pluralismo religioso, la aconfesionalidad del Estado y la libertad religiosa consagrada como derecho fundamental. El objetivo general del artículo es, a partir del convulso panorama internacional generado por conflictos como el ruso-ucraniano, analizar la interacción actual de estas iglesias y sus principales dinámicas al hilo de los flujos migratorios transnacionales, tales como el aumento de los números de fieles y de templos y los cambios en las estructuras eclesiásticas de representación e interlocución pública. Para ello, el abordaje metodológico del trabajo atenderá a distintos casos representados por iglesias nacionales, como la rumana y la rusa; "autóctonas", casos de la Iglesia Ortodoxa Española y de la Iglesia Ortodoxa Hispánica; y pan-ortodoxas, como la griega; además de un conjunto de iglesias "recién llegadas" que, por el momento, cuentan con un menor volumen y grado de implantación.
\end{abstract}

\footnotetext{
* Este trabajo se inserta en el contexto del proyecto de investigación "Bases teóricas y metodológicas para el estudio de la diversidad religiosa y las minorías religiosas en España” (HAR2016-75173-P) del Ministerio de Ciencia e Innovación de España, 2017-2020.

** Doctor en Historia, Universidad Complutense de Madrid. Catedrático, Universidad de La Laguna, Islas Canarias; Facultad de Humanidades de la Universidad de La Laguna, San Cristóbal de La Laguna (Santa Cruz de Tenerife, España). ORCID: 0000-0002-9913-4580.

*** Doctor en Antropología Social y Cultural, Universidad de Granada. Profesor, Departamento de Antropología Social y Psicología Social, Universidad Complutense de Madrid (Madrid, España). Miembro del grupo Antropología, Diversidad y Convivencia (GINADYC). ORCID: 0000-0001-5289-1472.
} 
Palabras clave: pluralismo religioso, migraciones, redes transnacionales, cristianismo ortodoxo, cristianismo oriental.

\begin{abstract}
The case of the Orthodox and Eastern Churches in Spain is key for understanding the impact of migratory movements and transnational diasporas on the national particularities of the current patriarchates. In the public sphere, these are interrelated to a greater or lesser degree to a marked context of religious pluralism, non-denominationalism of the State and religious freedom enshrined as a fundamental right. The general objective of the article is, on the basis of a convulsive international panorama generated by conflicts such as that between Russia and the Ukraine, to offer an analysis of the current interaction of these churches and their main dynamics in the light of transnational migratory flows. This includes the increase in the numbers of faithful and of places of worship and the changes in the ecclesiastical structures of public representation and dialogue. For this purpose, the methodological approach of the work will focus on different cases represented by national churches, such as the Romanian and Russian churches; the "autochthonous" cases of the Spanish Orthodox Church and the Hispanic Orthodox Church; and pan-orthodox cases, such as that of Greece. Also included will be a group of "newcomer" churches that, for the moment, have a smaller volume and degree of implantation.
\end{abstract}

Keywords: religious pluralism, migrations, transnational networks, orthodox Christianity, Eastern Christianity.

\title{
Introducción: el cristianismo ortodoxo en contextos de pluralismo religioso
}

La configuración de la cristiandad ortodoxa y oriental como iglesias autocéfalas, es decir, regidas por sí mismas de modo independiente de otras y bajo la jurisdicción de distintos patriarcados delimitados desde criterios de singularidad cultural, ha dotado a la ortodoxia de una gran capacidad de adecuarse a la diversidad nacional desde que el modelo moderno de Estado-nación ha ido configurando esferas geográficas en la que cristalizan y se encapsulan dichas singularidades culturales diferenciales. Estas particularidades por las que lo cultural y cultual se tiñen de lo nacional, se manifiestan también fuera de los territorios de tradición ortodoxa, coincidiendo con distintos movimientos migratorios y diásporas transnacionales que se extienden hasta Oriente Medio para el caso de las iglesias ortodoxas, y hasta África para el de las orientales, y también hacia países del norte y el sur del continente americano y del occidente europeo, destacando el ámbito al que se dedica este artículo, el español.

En estos territorios que la ortodoxia configura como diócesis metropolitanas, vicariatos o puntos de misión, las iglesias coexisten junto a muchas otras confesiones y grupos religiosos con diferentes grados de implantación y distintas necesidades y demandas sociales. Un "mercado religioso" plural (Berger, 1967; Luckmann, 1973) que es el resultado, en gran medida, de los contextos sociales de recepción de las migraciones actuales, marcados por la manera en que las sociedades occidentales definen la presencia de lo religioso en su espacio público (Casanova, 2007). Este pluralismo ha devenido en "súper-diverso" de la mano de los flujos migratorios y las redes transnacionales, con "importantes variaciones en las tradiciones devocionales" que invitan a considerar creativamente la interacción de múltiples ejes de diferenciación (Vertovec, 2007, pp. 1034, 1049). En los países de Europa 
occidental como España, el mapa religioso se caracteriza por "la pluralidad de sacralidades, la fragmentación" (Moreno, 1998, p. 170) y por la "persistencia" de lo religioso como relación a lo sagrado, sobrenatural o sobrehumano bajo formas nuevas que han entrañado un proceso de "recomposición-descomposición" (Briones, 2002, p. 295).

En este sentido, España resulta un ejemplo interesante a la hora de ilustrar las estrategias llevadas a cabo por las diferentes iglesias ortodoxas y orientales para la implementación de sus propuestas en un país bien alejado de los ámbitos culturales tradicionalmente ortodoxos. Se parte casi de una tabula rasa, pues se trata de uno de los pocos ámbitos nacionales en los que la diversidad religiosa era mínima en un pasado relativamente reciente, y en donde, con el cambio hacia un modelo de pluralidad religiosa desde la reinstauración democrática, se establecieron las bases jurídicas y convivenciales para el desarrollo con menos trabas de la diversidad religiosa. Además, los cambios económicos de los últimos cuarenta años convirtieron al país en un territorio de inmigración, en el que hay que añadir que la multiplicación de la diversidad cultural y de creencias se potenciaba por el enorme desarrollo del turismo. Desde el punto de vista del crecimiento de las iglesias y las confesiones religiosas, España se transformó desde un ámbito marginal hacia uno de los más dinámicos y hasta se podría decir que centrales, en el que la inversión en recursos por parte de las distintas confesiones, y en particular de los ortodoxos, se justificaba tanto desde el punto de vista de la necesidad de asistencia a un número creciente de fieles, como también desde la eficacia simbólica de apostar por ser bien visibles en un país europeo progresivamente más prestigioso y abierto, acogedor de las propuestas religiosas diferentes (Díez de Velasco, 2012).

En este contexto, las distintas confesiones están sujetas a un marco jurídicoinstitucional determinado por la aconfesionalidad del Estado y las garantías del derecho de libertad religiosa y culto (Contreras-Mazarío, 2011), lo que plantea a las instituciones públicas nuevos "retos y desafíos", como la apertura de lugares de culto o la financiación de las confesiones (Astor y Griera, 2016, p. 251) y una implicación más explícita que se materializa en una "nueva forma de gestión que favorece una aproximación más democrática e inclusiva hacia este fenómeno" (Astor y Griera, 2016, p. 247). Es aquí donde las confesiones religiosas "minoritarias", 1 especialmente las que cuentan con un mayor grado de consolidación en España, casos del islam (Salguero, 2018) o como el que aquí nos ocupa del cristianismo ortodoxo originario de Rumania o Rusia, entablan con mayor o menor éxito una serie de procesos de participación que requieren la negociación por la presencia efectiva en el espacio y la esfera públicas con distintos actores: las otras confesiones, los habitantes muchos de ellos fieles en potencia- y muy especialmente con los poderes públicos. Es el caso de la constitución en 2010 de la Asamblea Episcopal Ortodoxa de España y Portugal, un ente que ha intentado cumplir con éxito limitado el objetivo de facilitar la organización

\footnotetext{
${ }^{1}$ Confesiones religiosas "minoritarias", o "no mayoritarias", hace referencia a aquellos grupos religiosos distintos al que históricamente, por diversos motivos, ha sido la confesión mayoritaria en la sociedad española, en este caso, la Iglesia católica. Como resultado de ello, las confesiones minoritarias registran cifras menores en lo relativo al número de comunidades religiosas y lugares de culto existentes en el Estado español: según datos del Registro de Entidades Religiosas (ver https://www.mjusticia.gob.es/cs/Satellite/Portal/es/areastematicas/libertad-religiosa/registro-entidades-religiosas), en febrero de 2020 constaban inscritas un total de 13.842 entidades católicas, junto a las 5.010 entidades de otras confesiones, por su parte en el directorio de lugares de culto del Observatorio del Pluralismo Religioso en España (http://www.observatorioreligion.es/directorio-lugares-de-culto/) se incluyen 7.522 lugares. En ningún caso en este trabajo se otorga un valor subalternizante o peyorativo al término minoritario.
} 
eclesiástica de cara a la representación de los ortodoxos y sus comunidades ante el Estado y la sociedad, es decir, actuar como interlocutor oficial de los ortodoxos en España, asunto en buena medida puesto en entredicho por una significativa parte de la ortodoxia en España, que conforman las iglesias rumana y rusa y que, en los últimos años, como veremos, han puesto en marcha una federación nueva desde finales de 2018.

La ortodoxia, en el contexto general de la conformación del estudio de las minorías religiosas en España como un campo de investigación emergente y destacado (Díez de Velasco, 2017), presenta un interés especial, pero también ha requerido de la puesta en marcha de investigaciones específicas, como ahora veremos.

\section{Cuestiones metodológicas y contextos de investigación}

Este estudio enraíza en tres contextos de investigación interconectados. En primer lugar, parte del acervo de una primera investigación realizada entre los años 2012 y 2015 que fructificó en el libro titulado Las iglesias ortodoxas en España (Díez de Velasco, 2015), cuyos datos se utilizan y ponen al día en este artículo. Se trató de un trabajo sistemático de investigación, fruto de un contrato de investigación entre la fundación pública, en ese entonces adscrita al Ministerio de Justicia del Reino de España y en la actualidad dependiente del Ministerio de la Presidencia, Relaciones con las Cortes y Memoria Democrática, denominada Pluralismo y Convivencia ${ }^{2}$ y la Universidad de La Laguna (Islas Canarias, España). El abordaje metodológico de este trabajo, que también se sigue en el presente artículo, partía del enfoque transdisciplinar resultante de la sinergia de las miradas de la historia de las religiones y la antropología de la religión. Para ello, se conformó un equipo con cinco especialistas en los estudios sobre las minorías religiosas en contextos de diversidad, con diferentes perfiles académicos y profesionales. El equipo de investigación estuvo formado por Victoria Contreras, Francisco Díez de Velasco, Sergio Pou y Roberto Rodríguez de la Universidad de La Laguna, y por Óscar Salguero, entonces adscrito a la Universidad de Granada y hoy profesor del Departamento de Antropología Social y Psicología Social de la Universidad Complutense de Madrid. ${ }^{3}$

Una intensa labor de revisión bibliográfica (que contribuyese, entre otras cuestiones, a enmarcar históricamente la ortodoxia en España) y, sobre todo, documental (en organismos como el Registro de Entidades Religiosas del Ministerio de Justicia) precedió al trabajo de campo, del que también en gran medida se ha nutrido este artículo. Realizado entre finales del año 2012 y comienzos del 2014, extendiéndose a gran parte del territorio español, hubo que zonificar el mapa del país, asignando una determinada área de estudio a cada investigador; además de asignar un patriarcado en particular o, en su caso, un conjunto de iglesias (como las orientales) a cada miembro del equipo de investigación. El abordaje teórico, que es también el del presente artículo, adaptó la estructura y las técnicas clásicas de las investigaciones etnográficas. A lo largo de gran parte de la geografía española se visitaron numerosas parroquias (en iglesias propias y, sobre todo, en espacios cedidos) y lugares relacionados con el mundo ortodoxo (escuelas de iconos, monasterios, vicariatos, etc.); se

\footnotetext{
${ }^{2}$ Ver https://www.pluralismoyconvivencia.es/.

${ }^{3}$ Se agradece a los tres miembros del equipo de investigación que no aparecen como firmantes de este artículo (Victoria Contreras, Sergio Pou y Roberto Rodríguez), los datos y planteamientos que derivan de sus aportaciones y que se utilizan en este texto. Sus contribuciones publicadas son cumplidamente citadas en el texto.
} 
observaron diversos oficios religiosos, como la divina liturgia del domingo, y también importantes festividades como la Pascua. Además de la observación directa, las entrevistas formales y semiestructuradas tuvieron un importante papel en el trabajo de campo, las cuales partían de guiones específicos en función del patriarcado y del perfil del informante. Entre los informantes clave que nos acompañaron en gran parte del proceso y las personas entrevistadas se encuentran desde párrocos hasta responsables en España de cada una de estas iglesias: tanto los principales patriarcados -el de Constantinopla, el de Moscú y la Iglesia Ortodoxa de Rumania-, como de las congregaciones propiamente españolas -la Iglesia Ortodoxa Española o la antigua Iglesia Ortodoxa Hispánica- o de otras con menor implantación, como las de la Iglesia Copta, la Armenia, la Búlgara o la Georgiana. El resultado final fue un trabajo que, a la vez que situó históricamente la ortodoxia cristiana en España, ofreció una imagen de la cristiandad ortodoxa en la España actual que, sin pretensiones de exhaustividad, resultaba representativa de su realidad sociológica.

Cinco años después, ante los significativos cambios que ha sufrido la ortodoxia en los ámbitos español e internacional, ha resurgido la necesidad de retomar esta cuestión. Por tanto, el segundo contexto en el que se sustenta este artículo ha sido la puesta en común de los avances de investigación llevada a cabo en el Seminario "Observando religiones: las iglesias ortodoxas en España: cinco años después", desarrollado el 3 de mayo de 2019 en la Universidad de La Laguna. ${ }^{4}$ Se evidenció la necesidad de una nueva inmersión en la literatura y sobre todo la actualización de los datos sociodemográficos y registrales a través de fuentes como el Registro de Entidades Religiosas y el directorio de lugares de culto del Observatorio del Pluralismo Religioso en España. El análisis de estas fuentes ofreció unos primeros resultados que hablaban no solo del aumento del número de lugares de culto ortodoxos por prácticamente toda la geografía nacional, sino también de la aparición de nuevas estructuras como la Federación Ortodoxa de España y también de nuevas iglesias, como la Siriana, lo que ha traído consigo la realización de más entrevistas con nuevos informantes claves o con aquellos otros con quienes ya estuvimos y a quienes nos hemos dirigido nuevamente para que nos hablen sobre los cambios acaecidos en sus comunidades y los proyectos futuros.

El tercer contexto de investigación es el que determina el abordaje específico, muy centrado en las consideraciones teóricas, del presente trabajo, el cual tiene que ver con el proyecto de investigación actualmente en desarrollo en el que se incardina, titulado "Bases teóricas y metodológicas para el estudio de la diversidad religiosa y las minorías religiosas en España". ${ }^{5}$ La ortodoxia, por su notable posición en el contexto general del campo religioso español, presenta retos de interpretación desde el punto de vista teórico que justifican la pertinencia del abordaje que se plantea en este artículo, muy anclado en la reflexión teórica sustentada en el trabajo de campo y que no desdeña la comparación con otros grupos religiosos cuando resulta de relevancia.

\section{La visibilización de las religiones en España y el lugar de la ortodoxia}

En este contexto de investigación que acabamos de exponer resultó evidente una dinámica generalizada entre algunos grupos religiosos no mayoritarios con un significativo componente migratorio y nacional, en el que las cosmovisiones del país de origen continúan

\footnotetext{
${ }^{4}$ Ver http://historel.webs.ull.es/divrelesp/.

${ }^{5}$ Financiado por el Ministerio de Ciencia e Innovación de España y llevado a cabo desde la Universidad de La Laguna (http://historel.webs.ull.es/divrelesp/index.htm) del que el primer firmante es el investigador principal.
} 
desempeñando una notable influencia sobre los fieles y las estructuras religiosas gestadas en la diáspora, tal y como ejemplifican casos tan variopintos como el islam cuando se organiza en comunidades nacionales como la bangladesí (Salguero, 2019); y más especialmente los de iglesias cristianas como la anglicana, de membrecía mayoritariamente británica (Briones et al., 2010) o la que nos interesa en particular, ortodoxa, las cuales, en sus múltiples manifestaciones nacionales, cuentan con estructuras presbiteriales que implican "una organización nacional e internacional piramidal, donde existe una cabeza que regula y dirige la iglesia a partir de entidades organizativas que coordinen la labor" (Ramírez Fernández, López García, Herrero Galiano, Tello Weiss y Kirhlani, 2007, p. 140).

Esta dinámica se traduce en un movimiento pendular que va desde el mantenimiento por los distintos patriarcados nacionales de sus propios criterios de singularidad cultural y nacional hasta la reescritura de una serie de prácticas y discursos en el contexto migratorio en el que se insertan las iglesias ortodoxas. El papel de las migraciones y las redes transnacionales resulta por ello elemento fundamental: con el establecimiento y arraigo de algunos colectivos migrantes han venido consolidándose también las comunidades religiosas gestadas en su seno, por lo que las aspiraciones colectivas de iglesias, como la mayoritaria rumana, no se relacionan tanto ya con las vicisitudes de "la llegada", sino más bien con demandas de ciudadanía y reivindicación de derechos.

Tales demandas exigen la visibilización, el reconocimiento y la dignificación de sus singularidades identitarias nacionales y culturales, y pretenden ir más allá de la integración en el contexto ajeno de la sociedad receptora, apostando por su plena "inclusión" en un contexto intercultural construido entre los colectivos migrantes y la sociedad en general y al que ambas partes tendrán que adaptarse. ${ }^{6}$ En el otro polo se encontrarían las demandas de las iglesias más minoritarias y de más reciente implantación, que siguen estando más vinculadas a esa llegada, planteando como primera necesidad el contar con un lugar de culto, propio o, en su caso, cedido, pero con visos de permanencia.

En este orden, en el mercado religioso plural las confesiones no solo compiten por la adhesión de un mayor número de fieles, sino también por el acceso al suelo, considerado como un derecho de ciudadanía de la que ahora forman parte; esto es, como un "derecho a la ciudad" (Lefebvre, 1969). Un ejemplo de ello es el caso de la Iglesia Siriana Ortodoxa de Antioquía y todo Oriente en España, que desde que en 2015 se constituyera en España, se ha venido sucesivamente alojando en espacios cedidos por la Iglesia católica y, según se extrae de las entrevistas, contar ahora con un espacio más estable figura como su primer objetivo.

Gracias a la Iglesia católica que me ayudó mucho, tenemos un lugar, pero estamos buscando también un lugar propio. (...) ahora tenemos que ver otro camino, a ver si alguien puede donar o puede ayudar porque hemos visto que, a los rusos, a los protestantes, a los rumanos, el gobierno les ayudó. Entonces me parece que nosotros merecemos también un terreno o un edificio para tener nuestras actividades. (Arzobispo vicario patriarcal para España de la Iglesia Siro-Ortodoxa de Antioquía, Madrid. Entrevista del 9 de septiembre de 2019)

En el orden de estas demandas por el reconocimiento y la inclusión, la creciente visibilidad de la diversidad religiosa ha venido acentuada por el hecho de que "aquellos que optan seriamente por la religión en las sociedades europeas quieren hacer oír su voz tanto en

\footnotetext{
${ }^{6}$ Ver un ejemplo comparable revisado en Salguero (2018, p. 58).
} 
público como en privado" (Davie, 2004, p. 80). Esta demanda se materializa a través de diversas manifestaciones, también cultuales, como la procesión nocturna de la Pascua ortodoxa que desde hace algunos años recorre las calles de diversas ciudades españolas con un significativo volumen de población de origen rumano, caso del municipio de Fuenlabrada (Madrid) en donde, según datos extraídos del trabajo de campo, viene acogiendo en sus últimas ediciones en torno al millar de personas. Otra manifestación de esta creciente visibilización es la cada vez más frecuente participación de las iglesias ortodoxas en citas públicas de carácter ecuménico, como la Jornada de Oración por el Cuidado de la Creación en Madrid, el 2 de septiembre 2017 en el espacio público de la madrileña Casa de Campo, cuya liturgia estuvo oficiada por el archimandrita padre Demetrio del Patriarcado de Constantinopla; el cardenal Carlos Osoro, arzobispo católico de Madrid; el padre Macario de la Iglesia Ortodoxa Rumana y Nicolaos Matti, arzobispo de la Iglesia Siriana Ortodoxa de Antioquia y todo Oriente. Es decir, siguiendo a Casanova (2000), los grupos religiosos presentes en el territorio no están dispuestos a asumir acríticamente la tesis de la privatización de la religión y reivindican su derecho a estar presentes y visibles en la esfera pública; y en el caso español, frente a la presencia consuetudinaria de la Iglesia católica, la reivindicación se multiplica entre las confesiones minoritarias buscando una mayor visibilización frente a la fuerza del discurso mayoritario.

En el caso del cristianismo ortodoxo, como en el de las otras minorías religiosas, esta visibilización pública se despliega en tres ámbitos principales (Díez de Velasco, 2010): el numérico (el sociodemográfico y de la implantación de cada una de estas iglesias); el jurídico (en la forma de relacionarse con los poderes públicos, los cuales, en ocasiones, poco o nada tienen que ver con sus homónimos de los países de origen); y, por último, el patrimonial, con la construcción y apertura de nuevos lugares de culto, algunos de los cuales, incluso, con la consideración de catedral, como veremos.

\section{Cristianismo ortodoxo y redes transnacionales}

Tanto las creencias y prácticas religiosas, como las instituciones confesionales, también viajan en los flujos migratorios transnacionales, dotándose de capital humano, simbólico y social, que se materializa en forma de relaciones dinámicas, conectándose transnacionalmente y entretejiéndose con las comunidades de migrantes. En el caso de España, aunque la presencia moderna de los ortodoxos se rastrea a través del papel de unas primeras legaciones consulares como la griega (Contreras-Ortega, 2015) y la rusa desde el siglo XVIII (Pou, 2015), en el momento actual, las migraciones desempeñan más que nunca un papel protagonista en los procesos de implantación y consolidación de estas iglesias.

Junto a las dos iglesias nacionales citadas, han venido cobrando especial relevancia otras como la rumana. A este respecto, encontramos que las instituciones religiosas también pueden fortalecer al colectivo migrante de diversas maneras, con recursos materiales (asistenciales y de sustento) y también sociales y simbólicos, facilitando "la reconstrucción de la identidad cultural y su inclusión en el nuevo contexto" (Ambrosini, 2008, p. 13). Así, parejo al aumento del colectivo nacional rumano, en el seno del mismo se han venido gestando numerosas comunidades de fieles ortodoxos que han dado como resultado más de cien parroquias, numerosos puntos de misión y la construcción de la catedral Santísima Virgen María en Madrid, la primera de esta iglesia fuera del territorio nacional rumano. Correlativamente, también han generado un flujo más o menos constante de párrocos, 
habitualmente acompañados por sus familias, que han sido formados en Rumania y trasladados a España para atender los nuevos puntos diocesanos (Rodríguez-González, 2015).

La Iglesia Ortodoxa Rumana ha construido también otros lugares de culto que si bien no cuentan con el alto rango catedralicio, dan buena cuenta de este significativo crecimiento: es el caso de la Parroquia Ortodoxa Rumana San Jorge de Alcalá de Henares (Madrid), fruto de la cesión municipal de una parcela en la actual zona de expansión urbana del municipio sobre la que construirían un templo financiado por los propios fieles, que inauguraron en abril de 2018, coincidiendo con la misa del Domingo de Ramos.

Cuando nos concedieron la parcela en el 2010, aquí no había casi nada. (...) No queremos un templo lujoso, con pan de oro y esas cosas. La iglesia ha de ser el reflejo de su feligresía y esta es en su mayoría gente trabajadora que ha venido a España por un futuro mejor para ellos y sus familias. (Párroco de la Parroquia Ortodoxa Rumana San Jorge, Alcalá de Henares. Entrevista del 16 de marzo de 2018)

Estas redes transnacionales han diversificado aún más el mapa del pluralismo religioso. En el caso de España, junto a la citada preeminencia de las iglesias con cierta trayectoria y un volumen significativo de fieles (griegos, rumanos, rusos o serbios), algunos conflictos de repercusión internacional, como la guerra civil en Siria o la inestabilidad política en Egipto, han contribuido a la implantación o reubicación y redefinición de "nuevas" iglesias, como la Iglesia Siro-Ortodoxa de Antioquía o la Iglesia Copta Ortodoxa, caracterizadas hasta el momento por un volumen manifiestamente menor de fieles que sus predecesoras y con una escasa implantación territorial. La globalización, la exportación de la ideología occidental, la deslocalización de la producción y la movilidad de la mano de obra, por su parte, también han propiciado esta diversificación de la cristiandad ortodoxa, y junto a las iglesias citadas, han comenzado a ostentar cierta visibilidad otras como la Iglesia Ortodoxa Georgiana o la Iglesia Ortodoxa Búlgara en España (Salguero, 2015) o, más recientemente, la Iglesia Apostólica de Armenia en España y Portugal.

El conjunto de las iglesias ortodoxas y orientales, cada una con sus particularidades culturales y nacionales propias, está subsumido ahora en un nuevo y común contexto, determinado en lo sociológico por la pluralidad, y en lo legal y político por la aconfesionalidad del Estado y el derecho fundamental de libertad religiosa y de culto. La sinergia de estas circunstancias exige, por una parte, la coordinación entre las iglesias a efectos de una interlocución única ante los poderes públicos españoles que represente, en la medida de lo posible, a esta heterogeneidad de cultos y creyentes, y que llevó a la puesta en marcha en 2010 de la Asamblea Episcopal Ortodoxa de España y Portugal y al reconocimiento del notorio arraigo en 2010 (Díez de Velasco, 2015). Por otra parte, empuja a las iglesias a implementar una serie de distintas estrategias orientadas a la adscripción del mayor número posibles de fieles implicados en un mercado religioso cada vez más plural y que, en el caso ortodoxo en España, les lleva a competir entre ellas por satisfacer la demanda de personas provenientes de muy diversos orígenes nacionales.

En este sentido, resulta particularmente interesante (y conflictual) el caso ucraniano, determinado por el enturbiamiento de las relaciones entre los patriarcados implicados, a causa de una serie de enfrentamientos entre los mismos, con el conflicto de Ucrania como epicentro. A la par, en lo relativo al acomodo de sus nacionales, estos basculan en opciones diversas: por un lado, los fieles procedentes de la región ucraniana del bajo Donéts, la "zona 
prorrusa”, acuden a las iglesias del Patriarcado de Moscú; por otro lado, los ucranianos y ucranianas procedentes de otras zonas del país y, por tanto, superiores en número a aquellos, se albergan en parroquias por toda España del Patriarcado Ecuménico, hasta el punto de que este colectivo migrante es actualmente la principal nacionalidad presente en esta red de iglesias. Una tercera vía es la protagonizada por quienes se adaptan a la realidad local circundante $\mathrm{y}$, a falta de iglesias de connacionales, en sus municipios acuden a la opción cultual que mejor encaje con sus intereses.

A partir de estas consideraciones de índole teórica sobre visibilización y transnacionalidad, este texto pretende, en primer lugar, reflejar el convulso panorama internacional de las relaciones entre los diferentes patriarcados ortodoxos y, en especial, el choque -recrudecido recientemente con el agravante del conflicto de Ucrania- entre el de Constantinopla y el de Moscú. Tras la contextualización del marco internacional, el texto analizará la interacción actual de las iglesias ortodoxas y orientales en España, prestando especial atención a una serie de significativos cambios al hilo de los flujos migratorios transnacionales que están reconfigurando el mapa de la cristiandad ortodoxa en nuestra sociedad, aumentando el número de fieles y con ellos también el de sus templos; y, a su vez, incidiendo claramente en las mismas estructuras eclesiásticas y sus relaciones con la sociedad y las instituciones públicas. Para ello, atenderemos a distintos casos representados por diversas iglesias nacionales, como la rumana y la rusa, además de otras como las "autóctonas", casos de la Iglesia Ortodoxa Española y de la Iglesia Ortodoxa Hispánica; o la griega, que tiende a apostar por una vocación panortodoxa que se encuentra en la raíz misma del Patriarcado Ecuménico de Constantinopla en el que se incardina. A su vez, se analizarán las instituciones organizativas y jurídicas relacionadas, tanto las gestadas en España para posibilitar las relaciones con el Estado y su reconocimiento, como las que evidencian los posicionamientos en el ámbito internacional.

\section{Particularidades nacionales e identidad común en el marco internacional}

Para ahondar en estas cuestiones es necesario abrir la perspectiva más allá del campo religioso español y analizar el panorama de un modo más general y holístico. La tendencia a la división es inherente al cristianismo en su conformación histórica, pero también se evidencia una no menos fuerte tendencia a reconocer una identidad común, ecuménica. Esta se manifiesta en el deseo, por ejemplo, de no renunciar, en general, a la comunión por parte de las iglesias ortodoxas, y a escala de todo el cristianismo, en el interés por buscar puentes ecuménicos ya sea entre grandes conjuntos, por ejemplo, entre las iglesias orientales, entre ortodoxos y orientales, entre ortodoxos y católicos o entre ortodoxos y evangélicos, junto a otras posibles combinatorias; o de modo general, al constituir mecanismos ecuménicos para todos los cristianismos que se encuentren interesados en ahondarlos. Ecumenismo frente a particularismo podrían ser las orientaciones que históricamente han entrelazado o separado a las iglesias cristianas.

En la actualidad, el impacto de dos notables procesos recientes ha redefinido este panorama e influido de modo claro en la cristiandad ortodoxa. La modernidad generó tanto universalismo como nacionalismos. En lo relativo al primero, con la conformación de las sociedades postindustriales, donde los límites nacionales se van diluyendo en favor de una destacable tendencia a la globalización, se ha venido construyendo una senda muy potente de fortalecimiento de las posiciones que reivindican el ecumenismo, y que, en el caso de la 
ortodoxia, inciden en la reivindicación de la posición honorífica del Patriarcado de Constantinopla, que se identifica justamente por el epíteto de "Ecuménico". Los nacionalismos, por su parte, configuraron un sofisticado cauce para las tendencias a primar los particularismos culturales que eran bien evidentes en la historia de la ortodoxia y contribuyeron a ahondar en las identidades diferenciales de una serie de iglesias autocéfalas, para las que resulta difícil defender que su conformación es un asunto que no tiene que ver con el proceso nacionalista desde el momento en que la identidad cultural encuentra la vía política de acorazarse por medio de la construcción de Estados nacionales. Pero en nuestras sociedades globalizadas, la fuerza de lo nacional también perdura -en no poca medida y en los últimos tiempos- con el resurgir de las agendas políticas de corte nacionalista, que parecen abrumadoramente presentes.

El enfrentamiento entre los patriarcados de Moscú y Constantinopla ya fue fraguado tiempo atrás, desde el momento en el que el primero, por el número de sus fieles a escala global y por la fuerza de su implantación, reivindicase una posición de mayor preeminencia en detrimento de la primacía simbólica del Patriarcado Ecuménico de Constantinopla. Este conflicto tuvo un momento álgido con la retirada de rusos y búlgaros del sínodo ortodoxo celebrado en Creta (Grecia) durante el mes de junio de 2016, determinando, por tanto, su fracaso. Las posturas encontradas en lo relativo al papel de Ucrania como ámbito autocéfalo evidenciaron la fuerza de pulsiones entre lo nacional y lo ecuménico. Las principales estructuras e instituciones ortodoxas en España durante la década de 2000 estaban conformadas por un arzobispado del Patriarcado Ecuménico de Constantinopla, operativo con esa denominación desde 2003; un obispado del Patriarcado de Rumanía desde 2008; una Asamblea Episcopal Ortodoxa de España y Portugal ya en ciernes desde 2009 y constituida en 2010; y en general, aunque con algunas fisuras, una interlocución unificada de los ortodoxos con las autoridades del gobierno español que llevó a este, a través de la Comisión Asesora de Libertad Religiosa, a reconocer el notorio arraigo de la Iglesia Ortodoxa, el 15 de abril de $2010{ }^{7}$

Sin embargo, la situación posterior, y de modo claro tras el sínodo de Creta y el conflicto ruso-ucraniano por la península de Crimea, ha llevado a una serie de replanteamientos de estas relaciones. El 8 de octubre de 2018 se inscribió en el Registro de Entidades Religiosas del Ministerio de Justicia (número 24318) la denominada "Federación Ortodoxa de España", formada por rusos y rumanos; y el día 28 de diciembre de ese mismo año, el Patriarcado de Moscú convirtió en diócesis a la de Madrid y Lisboa (escindiéndola de la de Corsún con sede en París), con un arzobispo al frente, monseñor Néstor Sirotenko, que hasta ese momento había sido obispo de Corsún. Con ello, la imponente Iglesia de Santa María Magdalena de Madrid, fruto también de una cesión municipal en la Gran Vía de Hortaleza, pasaba a ser catedral ortodoxa rusa, como su homónima rumana, mientras que la máxima jerarquía rusa en España (y Portugal) se equiparaba en nivel al de la máxima jerarquía del Patriarcado Ecuménico de Constantinopla en España (y Portugal), en ambos casos con el rango de arzobispos y con la particularidad en el caso ruso de que se pasaba de una vicaría general para España y Portugal dependiente del obispado con sede en París a un arzobispado con sede en Madrid. El peso de lo nacional y lo ecuménico han redefinido sus

\footnotetext{
${ }^{7}$ Con este reconocimiento público estatal, el cristianismo ortodoxo en España se equipararía a otras confesiones reconocidas previamente con el notorio arraigo, pero sin acuerdo de cooperación con el Estado suscrito (como sí lo tienen evangélicos, judíos y musulmanes), concretamente: mormones o La Iglesia de Jesucristo de los Santos de los Últimos Días (2003), Testigos Cristianos de Jehová (2006) y budistas (2007).
} 
posiciones en el campo religioso español, convirtiéndolo en un interesante y simbólico laboratorio de interacciones y choques, sin que pueda suponerse que se trate de un mero ajuste coyuntural asociado al auge de los argumentos nacionalistas o pueda llegar a vehicular otros asuntos más estructurales que puedan determinar una duradera ruptura de la comunión entre estos patriarcados ortodoxos.

En este contexto se ha gestado una fórmula alternativa. Hay que tener en cuenta que, junto a los pasaportes y las fronteras, con las lenguas y las señas culturales propias que marcan ámbitos de identidad diferencial se entremezclan las corrientes migratorias, naciones en hibridación en las que la facilidad de las comunicaciones contribuye a construir puentes de ida y vuelta. Y es que con la consolidación de los múltiples mecanismos de lo global destaca, en el ámbito que nos interesa, el derecho a la libertad religiosa y de culto, amparado por el artículo 16 de la Constitución española como derecho fundamental y por declaraciones internacionales como la Declaración Universal de los Derechos Humanos, que en su artículo 18 establece la libertad de religión o de conciencia. Migrar no equivale ya a abandonar la religión de la patria de origen, como podía ocurrir en muchos casos en el pasado y en particular en nuestro país, donde hasta hace pocas décadas ser español se identificaba con una opción determinada e integrarse implicaba necesariamente olvidar esa parte de las raíces que tenía que ver con las creencias religiosas diferentes.

La religión se convierte así en un elemento de peculiaridad identitaria diferencial más aceptable frente a otros menos fáciles de mantener como la lengua, que se diluye entre las generaciones jóvenes que tienen como vehicular y cotidiano el español, quedando la lengua de sus antepasados en un progresivo olvido. La religión justamente juega el papel de territorio familiar en el que el lugar de culto es también en alguna medida parte de la patria dejada atrás $\mathrm{y}$, en ocasiones, añorada.

Los niños que nacen aquí ya no van a regresar a su país, ¿por qué? Porque viven aquí, es su cultura, hablan español cuando juegan. Aquí tenemos escuelas dominicales para no olvidar su lengua. Ahí estudian su lengua, estudian georgiano, historia de la Iglesia y del país. (...) y aquí tenemos clases de baile también, bailes tradicionales de Georgia. (Archimandrita de la Iglesia Ortodoxa Georgiana, Madrid. Entrevista del 29 de octubre de 2019)

Así, frente a la globalización imperante y la referencia nacional diluida en la migración, se instala la potencia de lo transnacional. Religiones transnacionales que "no necesitan pasaporte" (Levitt, 2009) para materializarse en iglesias en España pobladas de fieles, en su caso, de origen rumano, ruso, búlgaro, ucraniano, georgiano, armenio, sirio, egipcio, entre otras. Pudiera llegar a parecer en una aplicación estricta, pero con tendencia a confundir cultura y nación, que el ámbito de una iglesia autocéfala se podría encerrar entre los límites de una frontera, pero no es así en nuestro mundo marcado por lo transnacional. Salir del país, del ámbito territorial nacional, no implica necesariamente salir del ámbito cultural específico, no conlleva integrarse en una comunidad ecuménica en la que se diluyan las diferencias en pos de lo común. Ser ortodoxo y venir a España no es por tanto depender necesariamente del servicio global que ofrece el Patriarcado Ecuménico de Constantinopla.

Venir a España para una persona que quiere mantener su práctica religiosa en el cristianismo ortodoxo ruso, por ejemplo, ya sea como migrante o como turista, como trabajador o como jubilado de larga estancia, es encontrarse ante una oferta real múltiple, 
mayor en unas zonas que en otras, y que puede requerir más largos o menores desplazamientos para hallar lo que más se acerca a lo deseado.

\section{Lo global, lo nacional y lo transnacional}

Se evidencia, por tanto, una triple pulsión en las dinámicas de los siguientes tres elementos: lo global, lo nacional y lo transnacional. La pulsión hacia lo global se manifiesta en el caso de la red de párrocos que ha puesto en marcha el Patriarcado Ecuménico de Constantinopla, que ofrece cobijo natural a todo ortodoxo que busca configurar lenguajes comunes y que se acerca también a las necesidades particulares de fieles específicos que no encuentren centros afines en su zona, utilizando diversos idiomas y diferentes maneras de expresión ad hoc.

(...) al principio los armenios celebraban sus misas en la Iglesia Griega Ortodoxa, porque en aquel tiempo no tenían sacerdote, entonces pidieron al sacerdote griego que celebrase una misa en griego, por el otro rito, pero introduciendo en el coro partes de la misa armenia. (Vicario general de la Iglesia Apostólica de Armenia en España y Portugal, Madrid. Entrevista del 29 de septiembre de 2019)

La segunda de las pulsiones es hacia lo nacional. El Patriarcado Ecuménico de Constantinopla también presenta sus trazos nacionales, tanto en el servicio a la comunidad griega, que ha sido el que históricamente ha tenido mayor importancia en España, como a la ucraniana, de ahí que la pulsión hacia lo global se matice con estas particularidades que conllevan que sus iglesias se llenen en mayor medida cuando lo nacional se combina como ingrediente principal con lo ecuménico.

Esta pulsión hacia lo nacional se transforma al trasladarse a España en combinación con lo transnacional. Si bien las iglesias adscritas al Patriarcado de Rumania y al de Moscú buscan satisfacer la pulsión transnacional, la pulsión global también se manifiesta de dos maneras: bien empleando en la liturgia lenguas de un pasado común, como es el caso de las iglesias rusas, con el uso en el culto de la lengua eslava eclesiástica en vez del ruso; o bien, mediante el uso del español, un recurso cada vez más empleado por muchos párrocos de todas las tradiciones ortodoxas, por resultar la única lógica para que las nuevas generaciones no sientan la vivencia religiosa como una vivencia ajena, vehiculada en palabras cada vez más lejanas e incomprensibles. Estamos ante nuevas generaciones que pueblan trayectorias de inmigración de largo recorrido, en las que las patrias de origen y adopción se hibridan de un modo que puede primar la mirada globalizadora, que pasa por encima de naciones e identidades diferenciales, como demuestra el caso de la Iglesia Ortodoxa Rumana, cuya asociación juvenil, Nepsis España, organizó en diciembre de 2017 un Congreso PanOrtodoxo dirigido a todos los jóvenes ortodoxos de España.

La tercera de las pulsiones se dirige a lo transnacional, que pudiera parecer que se caracterizaría porque el territorio español sobre el que se instala se imagina como una provincia del territorio central y por ello dependiente en gran medida de allá. Los párrocos, tanto rumanos como rusos, son migrantes en su práctica totalidad, ordenados en sus países de origen y enviados a España por los respectivos órganos eclesiásticos centrales, quedando lejos de los espacios de formación enmarcados en un elemento clave en la ortodoxia, la red de monasterios. Estos referentes, por tanto, se ubicarían en Rumania, en Rusia o en el Monte Athos (Grecia), pero no en España. Parecería entonces que solo se debería configurar una 
parte de la estructura eclesial, solo la red parroquial, que crecería al unísono que lo hace la inmigración y que, por ese mismo criterio, decrecería si se produjese un retorno masivo a la patria de origen. Pero el panorama de lo transnacional es más complejo y hay que tener en cuenta que las religiones en migración tienden a adaptarse a la par que a mantener sus señas de identidad. Del mismo modo que ocurre cuando se opta por el uso del español en el culto, caben convergencias. Partiendo de que sería difícil que la vida de la iglesia hubiera podido mantenerse sin monasterios, que es donde se forman los futuros líderes (Binns, 2010), la ortodoxia rumana está desde 2014 poniendo en marcha un incipiente, pero creciente proceso de inscripción de lugares a los que otorga la denominación de monasterios (se han registrado tres: denominados monasterios ortodoxos rumanos de Santa Parascheva de Vilaller en Lérida -número 22375-, del Santo Jerarca José el Nuevo de Partos en Onzonilla, León -número 22373- y el de La Natividad del Señor en Villalbilla, Madrid -número 22374). Por su parte, la Iglesia Ortodoxa Española contaba entre sus propósitos la creación del primer monasterio ortodoxo en Cataluña (Salguero, 2015), y otras más minoritarias, como la Iglesia Ortodoxa Hispánica, llegó a tener entre los años 2011 y 2018 el pequeño monasterio de San Isidoro de Sevilla en la localidad del Castillo de Las Guardas, en la sierra norte de Sevilla (Salguero, 2015), actualmente en venta por la dificultad para encontrar dos monjes que velen permanentemente por el espacio, según se extrae de las entrevistas.

Por tanto, nacional, transnacional y global se combinan en una triple pulsión, evidenciando que el mundo de lo real está conformado por contextos en mezcla, y que las clasificaciones, por ser teóricas, sirven para producir marcos útiles para entender un panorama general, pero que cuando se desciende a los detalles, las situaciones pueden ser variadas, y podemos así, por ejemplo, encontrar españoles sirviendo en iglesias ortodoxas nacionales en posiciones de gran relevancia. Tales son los casos del vicario Makary (Joan Roselló Rigó) del Patriarcado de Moscú (Pou, 2015), del archimandrita Demetrio (Rogelio Sáez Carbó) del Patriarcado Ecuménico de Constantinopla (Contreras-Ortega, 2015) o del vicario general de la Iglesia Ortodoxa Española (Joan García) del Patriarcado de Serbia (Salguero, 2015).

Los perfiles personales y las historias de vida son también relevantes a la hora de entender que, frente a una enorme mayoría de migrantes, turistas y rentistas ortodoxos, encontremos también conversos, españoles que por diversas circunstancias han encontrado en la ortodoxia un mejor acomodo que lo que les ofrecían sus creencias anteriores, como son los casos de muchos clérigos de la Iglesia Ortodoxa Española adscrita al Patriarcado de Serbia o de la práctica totalidad de los de la Iglesia Ortodoxa Hispánica, ahora bajo la jurisdicción del Patriarcado Ecuménico de Constantinopla. Parece así emerger un nuevo perfil, el del ortodoxo español, que nos introduce en un nuevo elemento a tener presente en este análisis: lo local.

\section{El camino hacia lo local}

En efecto, en el caso español se constata un nuevo camino hacia una ortodoxia local, incipiente, pero de enorme interés. Y es un camino que lleva visibilizándose también en muchos otros territorios geográficos de más allá de los tradicionales de la ortodoxia, en Europa occidental y América, en particular. En el país en que más patente se revela el proceso es en los Estados Unidos de América, donde en torno al millón de fieles (según fuentes del propio colectivo, otras fuentes lo reducen a una octava parte) se identifican con la Iglesia 
Ortodoxa en América (Orthodox Church in America), cuya autocefalia ha sido reconocida por el Patriarcado de Moscú desde 1970, además de por otros patriarcados eslavos, pero no por el de Constantinopla (Pou, 2015).

Un caso de gran interés estudiado, ya con cierto detalle (Salguero, 2015), lo ofrece la Iglesia Ortodoxa Hispánica, gestada en el territorio andaluz con anterioridad a la consolidación de otras iglesias procedentes de países de Europa del Este que se gestaron gracias al auge de los flujos migratorios. Se evidencia cómo esta iglesia se propuso desde sus inicios hasta su reciente adscripción al Patriarcado Ecuménico de Constantinopla en 2016, una reivindicación de la ortodoxia en el territorio hispano que hasta en el nombre buscaba entroncar con unas primeras raíces cristianas de un pasado en el que las divisiones posteriores no cumplían, reivindicando figuras hispanas de la ortodoxia como San Osio de Córdoba (que recordemos que no está reconocido todavía como santo por la Iglesia católica).

Ahora mismo, la mayoría de las personas que vienen aquí son extranjeras. (...) españoles poquitos, españoles donde van más es en Sevilla. La liturgia se celebra en castellano. Aquí sí. Algunas cosas a veces se pueden decir en griego si sabemos el canto, pero, en fin, la liturgia es en castellano. El Padre Nuestro se reza también en rumano. (Párroco de Santa Madre de Dios y Santa Melania La Joven, Jerez de la Frontera, Patriarcado Ecuménico de Constantinopla. Entrevista del 16 de agosto de 2019)

La adhesión al Patriarcado Ecuménico de Constantinopla no parece haber traído consigo para la Iglesia Ortodoxa Hispánica su fagocitación. El mantenimiento de su territorio pastoral a las provincias de Sevilla y Cádiz, la creación de un nuevo "núcleo parroquial de la provincia de Cádiz" en Jerez de la Frontera (parroquia de la Santa Madre de Dios y Santa Melania La Joven) y la presencia activa de clérigos, diáconos y fieles españoles, sevillanos y jerezanos, sumado a la conservación de su identidad particular en el seno del Patriarcado Ecuménico, permiten seguir hablando al respecto de la misma como un "proyecto religioso autóctono" (Salguero, 2015, p. 361). Sin embargo, habrá que prestar atención al mayor o menor peso que una identidad particular, como la de la Iglesia Ortodoxa Hispánica, con una previa larga historia singular, se inserta de modo pleno en el Patriarcado Ecuménico de Constantinopla, de mayores dimensiones; sin obviar, por supuesto, cómo este último lo encaja.

Otro caso relativamente similar es el de la Iglesia Ortodoxa Española que, conformada por una feligresía multinacional, también plantea una propuesta autóctona, eminentemente catalana (Estruch, Gómez i Segalà, Griera e Iglesias, 2007; Salguero, 2015). Pese a estar bajo la jurisdicción del Patriarcado de Serbia y llamarse "Española", hace tiempo que comenzó a establecerse en otras comunidades autónomas periféricas -Galicia, País Vasco y Canarias- que no son catalanoparlantes y en cuyas parroquias y misiones también colaboran sacerdotes procedentes de países eslavos, como Gorann Andjelkoviç en la Parroquia de San Marcos en Irún (Salguero, 2015). Recientemente, también se ha implantado en la capital del Estado, con la constitución de la Parroquia de los Santos Apóstoles de Madrid, ubicada en la céntrica calle de Núñez de Balboa, si bien, en la práctica, por el momento es solo un punto de misión, según se extrae de las entrevistas: 
Primero celebraban en la iglesia anglicana de Madrid, y después algunas veces en la rusa, en la catedral rusa, pero no tienen un lugar permanente, ni tampoco un párroco. La Iglesia mandamos a alguien dos o tres veces al año, incluso sacerdotes directamente de Serbia; es más para las grandes fiestas como la Pascua y la Navidad, para que la pequeña comunidad serbia tenga sus ritos importantes asegurados. (Vicario general para España y Portugal y fundador de la Iglesia Ortodoxa EspañolaPatriarcado de Serbia. Entrevista del 21 de febrero de 2020).

Esta última ubicación está relacionada con su conformación no solo como confesión religiosa de notorio arraigo como el resto de los ortodoxos, sino también en tanto que beneficiaria, además, de la inclusión (anómala, desde luego, en la que acompañó a la Iglesia griega, que finalmente ha terminado consolidándose como arzobispado de Patriarcado Ecuménico de Constantinopla, como hemos visto) en el Acuerdo de Cooperación con el Estado y la Federación de Entidades Religiosas Evangélica de España (FEREDE) de 1992, y también al formar parte desde 2010 de la Asamblea Episcopal Ortodoxa para España y Portugal. Un perfil de actor religioso ya plenamente institucionalizado y habituado a la interlocución pública (tanto a nivel estatal como en Cataluña) que requiere también su ubicación próxima a las instituciones públicas y religiosas relacionadas. Su presencia en Madrid es, por tanto, una clara apuesta por su visibilidad en todo el país, más allá de otras cuestiones como la reivindicación de los propios orígenes regionales y nacionales, y la idea base de consolidar una propuesta propia de un ámbito nacional determinado.

En el momento actual, por tanto, ambas iglesias, la Ortodoxa Hispánica y la Ortodoxa Española, están experimentando un profundo cambio en lo relativo a su propia identidad territorial, marcadamente regional, "hispánica" e incluso "andaluza" para la primera y "catalana" para la segunda.

\section{Conclusiones}

De nuestro estudio se deriva una serie de conclusiones principales. La primera tiene que ver con la puesta en evidencia de la combinatoria de lo nacional en contextos de migración. El cristianismo ortodoxo en toda su diversidad nacional está presente ahora también en los contextos de pluralidad religiosa de las sociedades occidentales de países alejados de los territorios tradicionalmente ortodoxos, como España, en donde, por un lado, perviven los particularismos nacionales que permiten diferenciar a las distintas iglesias nacionales existentes; y, por otro, existe un mismo marco sociológico, político y legal al que tienen que ajustarse estas iglesias en aras de su reconocimiento público y de su plena capacidad de obrar. El grado de implantación y consolidación de cada iglesia nacional, irá, por ende, generalmente parejo al del colectivo migrante al que responde, como ha dejado expuesto el caso de la Iglesia Ortodoxa Rumana.

La segunda conclusión lleva a detectar una contradicción, ya que en estos territorios del extremo Occidente se evidencia del modo más claro, y hasta paradigmático, un dilema que, además de caracterizar a la ortodoxia, conforma una incongruencia de base. Y es que iglesias en comunión pongan en marcha obispados (y hasta arzobispados) y, en general, estructuras eclesiásticas con una fuerte reivindicación de independencia en las mismas zonas que resultan extraterritoriales respecto de la zona geográfica acotada por el reconocimiento y consensuada y ratificada desde Constantinopla de su autocefalia. España (y Portugal), en este sentido, aparecen como piezas colocadas en el epicentro de un enfrentamiento de 
intereses y pareceres que en muy pocos años ha conformado un tablero en el que dos arzobispados y un obispado reivindican la preeminencia. En este orden, el obispado rumano apuesta por evidenciar la fuerza de su profunda implantación tanto en Portugal como en España y exige el liderazgo en la interlocución con las autoridades españolas, con el hándicap de que solo tienen reconocido el notorio arraigo y los pocos privilegios que de ello se derivan, en comparación con los ostentados por los dos grupos asociados desde 1992 al acuerdo de cooperación evangélico, antes citado, es decir, la Iglesia griega reconvertida en 2003 en arzobispado del Patriarcado Ecuménico de Constantinopla y la Iglesia Ortodoxa Española. Los rusos, por su parte, reivindican el peso global del Patriarcado de Moscú y dando el paso de convertir a España y Portugal en diócesis bajo un arzobispo, en el contexto de recrudecimiento de su choque con el Patriarcado Ecuménico de Constantinopla, con el telón de fondo de la cuestión ucraniana, que tiene en España una particular significación, dado que la población originaria de Ucrania que reside en España supera las 110.000 personas, mientras que los rusos no llegan a las 80.000 .

La tercera conclusión pone de relieve un contexto adversativo. La reciente creación de la Federación Ortodoxa de España aparece como un reto frente a la Asamblea Episcopal Ortodoxa de España y Portugal en lo relativo al liderazgo de la interlocución pública con las autoridades españolas. En el segundo caso, la presidencia está estipulada en manos del Patriarcado Ecuménico de Constantinopla, mientras que en el primer caso se ha establecido un sistema rotatorio en el que la presencia de un arzobispo ruso sería un elemento más de equilibrio en un campo religioso, como es el ortodoxo en España, en constante transformación.

En suma, frente a la lógica de lo ecuménico, que haría de España un territorio acotado al servicio religioso proporcionado por el Patriarcado Ecuménico de Constantinopla, frente a la reivindicación de lo transnacional que convierte a cada persona en elemento portador de una parte de ese territorio nacional acotado por la autocefalia allá donde vaya, emerge la opción por hacer de España (o quizá de Iberia o Hispania-Spania, demarcando una zona geográficamente coherente), un territorio susceptible de formar en él una iglesia ortodoxa propia, que se exprese en español, que puede además reivindicar viejas liturgias, como la mozárabe y viejas identidades compartidas.

\section{Referencias bibliográficas}

Ambrosini, M. (2008). Participación religiosa e integración de los inmigrantes. Una reflexión entre América y Europa, entre historia y actualidad. Migraciones, $\mathrm{N}^{\circ} 23,11-44$.

Astor, A. y Griera, M. (2016). La gestión de la diversidad religiosa en la España contemporánea. En J. Arango, R. Mahia, D. Moya y E. Sánchez-Montijano (comps.), Anuario CIDOB de la Inmigración 2016 (pp. 248-270). Barcelona: CIDOB. DOI: 10.24241/AnuarioCIDOBInmi.2016

Berger, P. (1967). The Sacred Canopy: Elements of a Sociological Theory of Religion. Garden City (NY): Doubleday.

Binns, J. (2010). Las iglesias cristianas ortodoxas. Madrid: Akal.

Briones, R. (2002). Significado y funciones de las religiones en el tercer milenio. En M. Luna (ed.), La ciudad en el tercer milenio (pp. 289-310). Murcia: UCAM. 
Briones, R, Tarrés, S., Macías, C., Fernández, E., Salguero, O., Briones, R. y Suárez, V. (2010). La diversidad evangélica en Andalucía. En R. Briones (dir.), ¿Y tú (de) quién eres? Minorías religiosas en Andalucía. (pp. 91-223). Barcelona: Icaria.

Casanova, J. (2000). Religiones públicas en el mundo moderno. Madrid: PPC Editorial.

Casanova, J. (2007). La inmigración y el nuevo pluralismo religioso: una comparación Unión Europea / Estados Unidos. Revista CIDOB d'Afers Internacionals, № 77, 13-39.

Contreras-Mazarío, J. M. (2011). Marco jurídico del factor religioso en España. Documentos del Observatorio del Pluralismo Religioso en España, $\mathrm{N}^{\circ}$ 1, 1-38.

Contreras-Ortega, V. (2015). El Patriarcado Ecuménico de Constantinopla. En F. Díez de Velasco (comp.), Las iglesias ortodoxas en España (pp. 83-116). Madrid: Akal.

Davie, G. (2004). New Approaches in the Sociology of Religion : A Western Perspective. Social Compass, 55(1), 73-84.

Díez de Velasco, F. (2010). The visibilization of Religious Minorities in Spain. Social Compass, 57(2), 253-267. DOI: 10.1177/0037768610362410.

Díez de Velasco, F. (2012). Religiones en España: historia y presente. Madrid: Akal.

Díez de Velasco, F. (ed.) (2015). Las iglesias ortodoxas en España. Madrid: Akal.

Díez de Velasco, F. (2017). Las minorías religiosas en España: un campo de investigación emergente. En F. Montero, J. de la Cueva y J. Louzao (eds.), La historia religiosa de la España contemporánea: balance y perspectivas (pp. 299-316). Alcalá de Henares: Servicio de publicaciones de la Universidad de Alcalá.

Estruch, J., Gómez i Segalà, J., Griera, M. e Iglesias, A. (2007). La ortodoxia. En J. Estruch (comp.), Las otras religiones. Minorías religiosas en Cataluña (pp. 59-86). Barcelona: Icaria.

Lefebvre, H. (1969). El derecho a la ciudad. Barcelona: Península.

Levitt, P. (2009). God Needs No Passport. Immigrants and the Changing American Religious Landscape. Nueva York: The New Press.

López, B., Ramírez Fernández, A., López García, B., Herrero Galiano, E., Tello Weiss, M. y Kirhlani, S. (2007). Arraigados. Minorías religiosas en la Comunidad de Madrid. Barcelona: Icaria.

Luckmann, T. (1973). La religión invisible: el problema de la religión en la sociedad moderna. Salamanca: Sígueme.

Moreno, I. (1998). ¿Proceso de secularización o pluralidad de sacralidades en el mundo contemporáneo? En A. Nesti (comp.), Potenza e impotenza Della memoria. Scritti in onore de Vittorio Dini (pp. 170-184). Roma: Tibergraph Editrici.

Pou, S. (2015). El Patriarcado de Moscú en España. En F. Díez de Velasco (comp.), Las iglesias ortodoxas en España (pp. 221-334). Madrid: Akal.

Rodríguez-González, R. C. (2015). La Iglesia Ortodoxa Rumana en España. En F. Díez de Velasco (comp.), Las iglesias ortodoxas en España (pp. 151-218). Madrid: Akal.

Salguero, Ó. (2015). Otras iglesias ortodoxas y orientales. En F. Díez de Velasco (comp.), Las iglesias ortodoxas en España (pp. 325-385). Madrid: Akal.

Salguero, Ó. (2018). Baitul Muqarram: el islam en el espacio público del barrio de Lavapiés. Revista de Estudios Internacionales Mediterráneos, $\mathrm{N}^{\circ}$ 25, 111-138. DOI: $10.15366 /$ reim2018.25

Salguero, Ó. (2019). Estrategias de institucionalización del islam en contextos migratorios: el caso de Baitul Muqarram. Revista Internacional de Organizaciones, $\mathrm{N}^{\circ}$ 22, 55-79. DOI: $10.17345 /$ rio22.55-79. 
Vertovec, S. (2007). Super-diversity and its implications. Ethnic and racial studies, 30(6), 1024-1054. DOI: 10.1080/01419870701599465.

\section{Cómo citar este artículo}

Díez de Velazco, F. y Salguero, O. (2020). Las iglesias ortodoxas entre lo global, lo nacional y lo transnacional: apuntes sobre el caso español. Revista Cultura \& Religión, 14(1), 41-57. 